\title{
JUDICIALIZAÇÃO E ATIVISMO JUDICIAL EM PERSPECTIVA: UMA ANÁLISE A PARTIR DAS EXPERIÊNCIAS DAS SUPREMAS CORTES DO BRASIL E DO CANADÁ
}

\section{JUDICIALIZATION AND JUDICIAL ACTIVISM IN PERSPECTIVE: A \\ PARTIAL ANAL YSIS OF THE EXPERIENCES OF THE SUPREME COURTS OF BRAZIL AND CANADA}

\section{EDITH MARIA BARBOSA RAMOS}

Pós-Doutora em Direito Sanitário pela Fundação Oswaldo Cruz FIOCRUZ/Brasília/DF. Doutora em Políticas Públicas pela UFMA. Mestre em Direito pela UFMG. Graduada em Direito pela UFMA. Professora do Departamento de Direito da UFMA. Professora e Vice-Coordenadora do Mestrado em Direito e Instituições do Sistema de Justiça da UFMA. Coordenadora do Núcleo de Estudos em Direito Sanitário (NEDISA/UFMA). Professora e Pesquisadora da Universidade CEUMA. Bolsista do BEPP/FAPEMA (Bolsa de Estímulo à Produtividade em Pesquisa - Edital nº 007/2018 - Produtividade). Membro Convidado da Rede Ibero-Americana de Direito Sanitário e da Associação Lusófona de Direito da Saúde - ALDIS. Presidente da Comissão de Bioética e Biodireito do Conselho Seccional da OAB/MA.

\section{PEDRO TROVÃO DO ROSÁRIO}

Doutor em Direito, Investigador do Centro de Investigação Ratio Legis - UAL, Professor Universitário -Universidade Autónoma de Lisboa (Rua de Sta. Marta, n 47 - 1150-293 Lisboa - Portugal; prosario@autonoma.pt - e Advogado na Trovão do Rosário \& Associados, Sociedade de Advogados, SP, RL.

SARA BARROS PEREIRA DE MIRANDA Mestranda em Direito e Instituições do Sistema de Justiça pela Universidade Federal do Maranhão - PPGDIR/UFMA. Integrante do Núcleo de Estudos em Direito Sanitário 
(NEDISA) da UFMA. Pós-Graduada em Direito Processual Civil pela Universidade Anhanguera-Uniderp. Bacharela em Direito pela Universidade CEUMA. Advogada pela OAB/MA.

\section{RESUMO}

A presente pesquisa por escopo analisar os fenômenos da judicialização e do ativismo judicial a partir das experiências da Suprema Corte do Canadá e do Supremo Tribunal Federal brasileiro. Observou-se que, em ambos os países, tem havido, nas últimas décadas, uma contínua expansão da autoridade do Poder Judiciário e da sua atuação em temáticas de natureza política até então abordadas apenas pelos Poderes Legislativo e Executivo, o que pode ser evidenciado a partir da análise das decisões proferidas pelas Cortes Supremas dos dois países. Apesar das diferenças na arquitetura constitucional, ambas as Cortes atuam como condutoras do processo de expansão alcance do poder de suas estruturas judiciárias. $O$ presente artigo foi desenvolvido a partir de levantamento bibliográfico em artigos obtidos em diferentes bancos de dados e indexadores, publicados na integra em português e inglês, acessados de forma gratuita. Foram selecionadas revistas científicas na área do Direito Constitucional Comparado com extratos elevados, qualis A e B. Utilizou-se, ainda, dados constantes em documentos oficiais e na legislação pertinente com recorte epistemológico e científico fundado na construção teórica contemporânea dos Direitos Fundamentais.

PALAVRAS-CHAVE: Judicialização; Ativismo Judicial; Suprema Corte do Canadá; Supremo Tribunal Federal brasileiro.

\section{ABSTRACT}

This research by scope analyzes the phenomena of judicialization and judicial activism from the experiences of the Supreme Court of Canada and the Brazilian Supreme Court. It has been observed that, in both countries, there has been, in the last decades, a continuous expansion of the authority of the Judiciary Power and its action in themes of a political nature hitherto addressed only by the Legislative and Executive Powers, which can be evidenced by from the analysis of the decisions of the Supreme Courts 
of both countries. Despite differences in constitutional architecture, both courts act as drivers of the process of expanding the power of their judicial structures. This article was developed from a bibliographic survey in articles obtained in different databases and indexers, published in full in Portuguese and English, accessed for free. Scientific journals were selected in the area of Constitutional Law Compared with high extracts, qualis $A$ and $B$. It was also used data in official documents and relevant legislation with epistemological and scientific basis based on the contemporary theoretical construction of Fundamental Rights.

KEYWORDS: Judicialization; Judicial activism; Supreme Court of Canada; Brazilian Supreme Court.

\section{INTRODUÇÃO}

A Polícia Federal do Estado do Pernambuco no Brasil realizou plantão especial no aeroporto de Guararapes em janeiro de 2004 após decisão do Juiz Federal Julier Sebastião da Silva, do Estado brasileiro do Mato Grosso, determinar que cidadãos dos Estados Unidos da América (EUA) que ingressassem no território nacional fossem fotografados e tivessem suas digitais coletadas. A decisão tinha validade por todo o território nacional e se propunha oferecer o mesmo tratamento recebido pelos brasileiros que ingressavam nos EUA aos norte-americanos que ingressassem no Brasil.

Embora a decisão tivesse como substrato a aplicação do princípio da reciprocidade, que estabelece o costume internacional dos Estados tratarem os estrangeiros da mesma forma que seus nacionais o são quando ingressam em território de outro país, observou-se uma clara atuação de interferência do Poder Judiciário na esfera de atuação do Poder Executivo, especificamente no Ministério das Relações Exteriores, responsável por editar o procedimento de inspeção dos estrangeiros que ingressam no Brasil.

Essa e tantas outras decisões apresentam o que cada vez mais se tem observado, sobretudo nos estados democráticos no final da segunda metade do século XX e neste primeiro quadrante do século XXI: a expansão da autoridade do 
Poder Judiciário em assuntos de natureza eminentemente política, que tradicionalmente são debatidos e decididos pelas instituições majoritárias (Poderes Executivo e Legislativo) (TATE; VALLINDER, 1995; HISCHL, 2009).

Nos Estados Unidos foi constatado que desde o século XX a Suprema Corte já realizava o controle de constitucionalidade das leis e atos normativos e assim como já se realizava a análise de razoabilidade dos princípios constitucionais (VIEIRA, 2008). No Brasil, a democratização promovida com a Constituição da República de 1988 levou a uma modificação da estrutura do Estado brasileiro como um todo, e, por consequência, dos Poderes da República. Fortaleceu-se a divisão de competências em torno da noção dada por Montesquieu de separação dos poderes em três: um poder cuja competência estava dirigida prioritariamente para a elaboração da lei, o outro com atribuições claras de execução da lei e gestão das políticas públicas definidas pelos governos no interesse da maioria da população e um terceiro poder encarregado da aplicação da lei em um processo dialético, o contencioso. E toda essa estrutura, em conjunto, compõe o Estado Democrático de Direito (FERREIRA FILHO, 1994).

$\mathrm{Na}$ medida em que compete ao Poder Judiciário o papel de árbitro, responsável pela verificação da compatibilidade entre as normas editadas e os direitos dispostos na Constituição, e que as respostas serão fornecidas pelas Supremas Cortes, no exercício do controle de constitucionalidade, as atenções voltaram-se, de forma inédita, aos juízes que irão decidir essas demandas e como irão decidir, tendo em vista que a repercussão das suas decisões pode atingir significativo número de pessoas, bem como gerar um elevado grau de insegurança jurídica (PINTO, 2013).

Em razão disso, com o escopo de contextualizar e analisar os fenômenos da judicialização e do ativismo nos países Brasil e Canadá a presente investigação materializou-se no formato de revisão sistemática, enquanto espécie de revisão de literatura. Procedeu-se uma análise histórica e conceitual das ideias de judicialização e ativismos no contexto de atuação dos poderes judiciários brasileiro e canadense, objetivando compreender os determinantes que propiciaram sua constituição, bem como a atualização do seu processo de desenvolvimento. Portanto, este texto concentra-se em uma oportunidade, do ponto de vista científico, para aquele que pretende discutir a expansão do Poder Judiciário e em que medida a construção 
teórica e jurisprudencial sobre o tema possui envergadura para dar conta dar das consequências do protagonismo do Poder Judiciário sobre as instituições majoritárias.

Tal oportunidade justificou o esforço científico aqui materializado no percurso metodológico necessário para pôr em questão o seguinte pressuposto: Na construção do protagonismo do Poder Judiciário sobre as instituições majoritárias foram constituídos dois fenômenos correlatos, mas distintos, quais sejam: a judicialização e o ativismo judicial, esses fenômenos representaram a consecução de um novo paradigma para atuação das instituições de justiça nas democracias ocidentais. Procurou-se, assim, verificar a articulação entre os fenômenos da judicialização e do ativismo, a partir da teoria da separação dos poderes e da experiência vivenciada pelos Estados brasileiro e canadense.

Em razão disso, a presente pesquisa utilizou o método de dedutivo, com a apropriação histórica de conceitos como judicialização, ativismo judicial e democracia. Para o levantamento de informações, os principais procedimentos de coleta de dados foram bibliográficos e documentais (LAKATOS, 2007). Para o levantamento bibliográfico foram utilizados artigos obtidos em diferentes bancos de dados e indexadores, publicados na integra em português e inglês, acessados de forma gratuita. Ademais, foram selecionadas revistas científicas na área do Direito Constitucional Comparado com extratos elevados, qualis $\mathrm{A}$ e $\mathrm{B}$, tendo como descritor de buscas, os termos: judicialização; ativismo judicial; Suprema Corte do Canadá; Supremo Tribunal Federal brasileiro.

Para cumprir o procedimento de coleta de dados foram analisados documentos oficiais e textos normativos expedidos por organismos nacionais de ambos os países, bem como documentos internacionais que tratam da temática da judicialização e do ativismo judicial. O conjunto de documentos e textos normativos coletados contemplou tratados, constituições, declarações, legislações e normas infralegais. Foram, assim, considerados válidos os documentos e textos normativos que permitiram o levantamento de informações no campo das dimensões indicadas na configuração do objeto pesquisado. Destaque-se que se procurou superar posturas metodológicas rígidas, demarcando a análise em diversas variáveis contextuais, quais sejam, jurídica, social, econômica e política, a fim de que se evitasse considerações 
maniqueístas e sem objetivação científica e se conseguisse empreender uma investigação socialmente situada.

O artigo foi estruturado nos seguintes tópicos: estrutura do Judiciário brasileiro e da atuação do Supremo Tribunal Federal (STF); estrutura do Judiciário canadense e da atuação da sua Suprema Corte; conceituação de judicialização e ativismo judicial, com análise dos referidos fenômenos; análise de ambos os fenômenos a partir da recente atuação do STF e da Suprema Corte canadense; considerações finais.

\section{O PODER JUDICIÁRIO BRASILEIRO E CANADENSE}

Como ponto de partida da presente análise, cumpre compreender o modelo constitucional adotado no Brasil e no Canadá para os seus respectivos Poderes Judiciários. Dessa forma, foi possível compreender o funcionamento de ambos, bem como fundamentar quais os fatores que levaram ao crescimento dos fenômenos da judicialização da política e do ativismo judicial nas Cortes Supremas dos dois países.

\subsection{PODER JUDICIÁRIO NO BRASIL E O PAPEL INSTITUCIONAL DO SUPREMO TRIBUNAL FEDERAL}

Assim como nos Estados de derivação liberal cuja estrutura pauta-se na ideia de separação dos poderes, aproximando-se da fórmula apresentada por Montesquieu na obra "Do Espírito das Leis", também se adotou no Brasil a mesma engenharia estrutural, dividindo-se as funções do Estado entre os Poderes Legislativo, Executivo e Judiciário (FERREIRA FILHO, 1994).

Ao Poder Legislativo compete a edição emendas constitucionais e de leis infraconstitucionais. Ao Poder Executivo, a elaboração e execução de políticas de governo e serviços públicos. Já o Poder Judiciário ficou responsável pela composição de conflitos de interesses em casos concretos, exercendo a função jurisdicional ou a jurisdição, que se realiza por meio de um processo judicial com a aplicação de ordens legais, gerais e abstratas (SILVA, 2016).

Essa concepção de separação dos poderes tem o seu valor e sua importância, pois aponta para uma preocupação do Constituinte Originário, no Brasil, em estabelecer mecanismos que sejam capazes de afastar os riscos para a democracia e para os direitos fundamentais ao estabelecer as competências dos Poderes. Assim, consolida-se a ideia de limitação dos Poderes do Estado, ao passo que se afirma o comando constitucional de que o poder emana do povo, conforme dispõe o parágrafo 
único do artigo $1^{\circ}$ da Constituição da República de 1988 (CRB/88), além de o Brasil se apresentar enquanto um Estado de Direito, expresso no caput do artigo $1^{\circ}$ da CRB/88 (BARROSO, 2012; FERREIRA FILHO, 1994).

Retomando o olhar ao Poder Judiciário, tem-se que a função jurisdicional é exercida por Juízes e Tribunais fundados em juízos de valor objetivos e imparciais, sem estabelecer critérios pessoais como fundamentos de suas decisões, pautandose nos critérios editados pelo legislador (SILVA, 2016). Tem-se, portanto, como principais características desse Poder: a função de árbitro, a pronúncia acerca de casos particulares e a inércia, atuando somente quando provocado (FERREIRA FILHO, 1994).

A Constituição da República brasileira prescreve diretrizes ao Judiciário que Ihe são capazes de garantir independência e autonomia administrativa e financeira, assim como ao Poder Executivo (SADEK, 2004). Na sua estrutura, o Supremo Tribunal Federal brasileiro (STF) é o órgão de cúpula que exerce função predominantemente constitucional e o Superior Tribunal de Justiça (STJ) é o órgão "de controle da inteireza, da autoridade e da uniformidade da interpretação da lei federal” (SILVA, 2016, p. 579).

Além desses, compõem o Poder Judiciário, conforme disciplina o artigo 92 da Constituição da República brasileira, os seguintes órgãos: Conselho Nacional de Justiça, Tribunal Superior do Trabalho, Tribunais Regionais Federais e Juízes Federais, Tribunais e Juízes do Trabalho, Tribunais e Juízes Eleitorais, Tribunais e Juízes Militares e Tribunais e Juízes dos Estados e do Distrito Federal e Territórios (BRASIL, 1988).

A partir da Constituição da República brasileira de 1988 foi inaugurada uma nova fase na jurisdição brasileira que reforçou o papel do Judiciário na arena política, delimitando-o como instância superior de resolução de conflitos entre o Legislativo e - Executivo e entre particulares e os referidos poderes, quando aqueles se sintam ameaçados ou tenham seus direitos constitucionais atingidos por decisões desses poderes (SADEK, 2004).

Dentre os órgãos que compõem o Poder Judiciário, destaca-se o STF, cuja função principal de guardião da Constituição da República o condiciona a sempre dar a última palavra em matéria de interpretação constitucional. Nesse sentido, sua atuação está atrelada ao controle de constitucionalidade das leis e atos normativos, que pode ser exercido tanto na modalidade difusa quanto concentrada, tendo em vista que o Brasil adota um sistema misto de controle (SILVA, 2016).

O art. 102 da Constituição da República brasileira disciplina que, dentre as matérias de competência do STF, Ihe cabe estabelecer os precedentes em matéria constitucional a serem seguidos pelos demais Juízes e Tribunais, assim como julgar Recursos e Ações Originárias cuja matéria esteja especificamente disposta no artigo supracitado. No exercício do controle concentrado de constitucionalidade, compete ao STF analisar de modo abstrato a compatibilidade de leis e atos normativos com a Constituição da República (SILVA, 2016). 
No controle concentrado, a decisão do STF possui eficácia erga omnes e efeito vinculante em relação a todos os órgãos do Poder Judiciário e da Administração Pública. Os legitimados que podem propor conhecimento acerca da constitucionalidade de uma lei ou ato normativo em abstrato estão dispostos no art. 103 da Constituição da República brasileira, dentre eles, destaca-se: o Presidente da República, o Governador de Estado ou do Distrito Federal e o Procurador-Geral da República.

As ações no controle concentrado além de possuírem legitimados específicos para sua propositura, também são em número de 5 (cinco) ações, cujos nomes já apontam para qual finalidade existem, quais sejam: a Ação Direta de Inconstitucionalidade, Ação Declaratória de Constitucionalidade, Ação Direta de Inconstitucionalidade por Omissão, Ação Direta de Inconstitucionalidade Interventiva e Ação de Descumprimento de Preceito Federal. (SILVA, 2016).

Por outro lado, com relação ao controle de constitucionalidade difuso, é dada a possibilidade de todas as instâncias do Poder Judiciário exercer o filtro de aplicação constitucional acerca de uma lei ou ato normativo em um caso concreto. Se decretada a inconstitucionalidade da lei, por exemplo, seus efeitos apenas atingem as partes que compõem o processo em que se discutia o tema. Além disso, os efeitos desta decisão são ex tunc e retroagem até o início da relação jurídica construída com base na norma inconstitucional (SILVA, 2016).

Dentro do contexto de estruturação do Poder Judiciário e do processo de controle de constitucionalidade das normas, o STF tem significativa importância nestes espaços e atividades, isso porque, conforme já mencionado, o seu papel institucional de guardião da constituição Ihe condiciona a ter um comportamento reto e imparcial nas questões que lhe são levadas a decidir (BARROSO, 2012).

A função de interpretar a Constituição da República brasileira de 1988 que é "analítica, ambiciosa, desconfiada do legislador" (BARROSO, 2012, p. 24) é um exercício de difícil consecução, pois em razão da gama de direitos nela presentes cada vez mais se abre a possibilidade de transformar política em matéria de Direito e, consequentemente essas matérias serão objeto de discussão pelos órgãos do Poder Judiciário, dentre eles o STF.

Ao discorrer a respeito do processo de constitucionalização do direito brasileiro inaugurado com a Constituição da República de 1988, Vieira (2008, p. 447) afirma que foi criado um espaço de tensão constitucional, onde "quase tudo" se tornou objeto de proteção constitucional e gerou uma explosão de litígios. Nesse sentido, afirma que:

A equação é simples: se tudo é matéria constitucional, o campo de liberdade dado ao corpo político é muito pequeno. Qualquer movimento mais brusco dos administradores ou dos legisladores gera um incidente de inconstitucionalidade, que, por regra, deságua no Supremo. Os dados são eloquentes. Em 1940, o Supremo recebeu 2.419 processos; este número chegara a 6.376 em 1970. Com a adoção da Constituição de 1988, saltamos para 18.564 processos recebidos em 1990, 105.307 em 2000 e 160.453 em 
2002, ano em que o Supremo recebeu o maior número de processos em toda sua história.

Somado a essa questão, a Constituição da República brasileira alargou demasiadamente as competências do STF e permitiu com que diversas ações para além do controle concentrado de constitucionalidade fossem objeto de seu conhecimento, seja por recurso ou por se tratar de competência originária do Tribunal. Isso se trata de problema presente na própria arquitetura institucional da Corte. Enquanto em outros países as competências sobre matérias constitucionais estão divididas em pelo menos 3 (três) instituições - tribunais constitucionais, foros judicias especializados e tribunais de recursos de última instância - no Brasil, o STF cumula, conforme disposto no artigo 102, inciso I da Constituição da República brasileira de 1988, 16 (dezesseis) matérias cuja competência é originária, cabendo apenas a esse Tribunal a sua discussão (VIEIRA, 2008; BARROSO, 2012).

Barroso (2012) e Carvalho (2004) mencionam que a democratização do direito no Brasil e o alargamento de competências do STF foram dois fatores que deram causa à judicialização da política no ordenamento jurídico brasileiro. Além disso, afirmam que o rol de legitimados do artigo 103, aptos a propor ações do controle concentrado, aumentou e permitiu com que mais pessoas tivessem acesso ao órgão de cúpula do Judiciário.

O que se verifica no âmbito do Poder Judiciário e, especificamente do STF, é que apesar de ter competências de um Tribunal Constitucional, a democratização dos direitos fundamentais, a ampliação de suas competências e dos legitimados do artigo 103 da Constituição da República brasileira, permitiram com que esse órgão não mais se tratasse de uma Corte, no sentido literal da palavra, mas sim uma espécie de instancia recursal extensiva, o que reflete diretamente na sua forma de atuação diante de determinadas questões, que serão objeto de melhor explanação no tópico que conceitua os fenômenos da judicialização da política e do ativismo judicial.

Apesar da reforma promovida no ano de 2004 pela Emeda Constitucional $\mathrm{n}$. 45, pouco se avançou na delimitação exata de uma Corte Constitucional no Brasil. Reconhece-se que as mudanças foram necessárias ao Poder Judiciário - a fim de que não viesse a sucumbir no exercício de sua função -, mas entende-se que essas alterações foram insuficientes, pois não conseguiram diminuir a significativa carga de 
demandas a serem resolvidas por seus órgãos. Tem-se que o STF, a partir de então, possui como mecanismo de admissibilidade dos recursos extraordinários a repercussão geral e também a possibilidade de fixar precedentes por meio das súmulas vinculantes. Reafirma-se que a iniciativa de reforma do referido Poder deveria promover um filtro maior acerca das demandas que deveriam ser objeto de conhecimento do STF, mas durou por pouco tempo - e questiona-se se foram efetivas desde o seu início -, na medida em que as demandas se tornaram ainda mais complexas e os filtros não foram suficientes para solucionar o problema que está na raiz da crise do Poder Judiciário brasileiro, qual seja: a própria estrutura e competências dos Tribunais (VERÍSSIMO, 2008).

\subsection{PODER JUDICIÁRIO NO CANADÁ E O PAPEL INSTITUCIONAL DA SUPREMA CORTE CANADENSE}

Da mesma forma que o Estado brasileiro e assim como nos países democráticos cujas bases são de origem liberal, o Canadá também adotou o princípio a Separação dos Poderes. Os Poderes Legislativo, Executivo e Judiciário são independentes entre si e, particularmente, ao Judiciário the é investido o poder de intérprete e aplicador da Lei nos casos concretos (GALL. 2017; BARBOSA, 2002).

A organização do Poder Judiciário no Canadá está disposta no Ato Constitucional de 1867 e suas competências estão distribuídas em Federal e Provincial. O seu órgão de cúpula é a Suprema Corte do Canadá e sua competência primordial é a de conhecer dos apelos originados de todos os Tribunais de Apelação das Províncias e do Tribunal Federal de Apelação. Abaixo desta Corte encontram-se o Tribunal de Apelação de Assuntos Marciais ou Militares, o Tribunal de Apelação Provincial e Tribunal Federal de Apelação (CANADA, 2017).

A Suprema Corte canadense é composta por 9 (nove) juízes que são nomeados pelo Governo Federal e sua jurisdição deriva, principalmente, do Ato da Suprema Corte, além de outros Atos do Parlamento. Em razão da sua independência funcional e da qualidade e estima do seu trabalho, a Suprema Corte contribui significativamente para que o país tenha bases fortes capazes de promover o exercício da democracia local (CANADA, 2017). 
Os juízes nomeados para a Suprema Corte canadense, para o Tribunal Federal ou para algum Tribunal Federal Provincial ou de Territórios ocupam seus cargos até os 75 (setenta e cinco) anos de idade, quando são aposentados obrigatoriamente. Dentre as exigências a serem cumpridas pelos juízes, o bom comportamento é obrigatório durante sua permanência no cargo. Além disso, se se tratar de um juiz nomeado pelo Governo Federal, sua saída somente será decretada pelo Parlamento, após recomendação do Ministro da Justiça e confirmação do Conselho de Justiça de Canadá (GALL, 2017).

Conforme apresentado, os juízes são nomeados pelos Governos Federal ou Provincial, a depender de quem seja a competência para nomeá-los. Por se tratar de um ato sigiloso, amplamente é sabido que o escolhido ou a escolhida para ocupar o cargo está ligado(a) à política, especialmente, ao partido político que ocupa o poder. Embora soe estranho, ninguém pode ser desqualificado de ser nomeado em razão de sua filiação política anterior (GALL, 2017).

A fim de discorrer melhor acerca da atuação do Poder Judiciário canadense e realizar-se o estudo comparado com o Brasil sobre os fenômenos da judicialização e do ativismo judicial, passa-se a apresentar o processo de construção do controle de constitucionalidade e do modelo adotado nesse país, cujos reflexos apontam diretamente a forma de atuação da Suprema Corte do Canadá.

Até 1937 o Canadá era reconhecidamente colônia da Inglaterra e não possuía autonomia constitucional perante sua Metrópole. Isso implica afirmar que as normas válidas na colônia eram derivadas da Inglaterra e aplicadas diretamente sem qualquer processo de adaptação aos costumes e tradições ali desenvolvidos. Contudo, em 1931 foi assinado o Estatuto de Westminster, que conferiu ao Canadá a sua autonomia parcial frente à Grã-Bretanha (BARBOSA, 2002).

A partir deste documento, tem-se uma modificação significativa na edição de normas no Canadá. Agora, não seria mais necessário que as normas editadas fossem compatíveis com as normas da Grã-Bretanha. Referido ato permitiu que em meados de 1980 o país iniciasse sua caminhada em busca da garantia de sua soberania no plano internacional e a unidade nacional, sobretudo em relação à Província do Quebec, que sempre buscou independência em relação ao restante do país (BARBOSA, 2002; PINTO, 2013).

Durante a Reforma Constitucional em 1982 foi criada a "Lei Constitucional de 1867", que teve sua origem a partir do disposto no "Ato da América do Norte de 1867". Juntamente, foram editadas a Lei Constitucional de 1982 e a Carta Canadense de Direitos e Liberdades, que constituem a atual Constituição do Canadá. A partir desse marco normativo, em 1982, o Canadá passou a exercer soberanamente o Poder 
Constituinte, permitindo-o realizar o filtro de aplicação das normas inglesas no país, repatriando ou refutando-as (BARBOSA, 2002).

Por meio desse ato se estabeleceu a quebra simbólica do Parlamento Canadense em relação ao Parlamento Inglês, pois agora poderia legislar e pautar os conteúdos que fossem de interesse à nação canadense. Dessa forma, aponta-se para a transição de um modelo constitucional político, derivado da experiência britânica, amparada na supremacia do Parlamento, para um sistema de constitucionalismo jurídico, onde a supremacia reside na Constituição (PINTO, 2013).

Antes da Carta de 1982 o modelo constitucional canadense era político e o poder do Parlamento era supremo em relação aos outros Poderes. Assim, suas decisões não poderiam ser revistas ou substituídas pelo Judiciário e/ou Executivo. Consequentemente, os atos constitucionais não eram dotados de rigidez e poderiam ser alterados pela maioria parlamentar. Assim como nos Estados Unidos não há disposição constitucional que anuncie ao Judiciário o papel de invalidar normas contrárias à sua constituição, no Canadá também não havia (PINTO, 2013; BARBOSA, 2002).

O judicial review no ordenamento canadense surgiu a partir do caso Vallin C. Langlois, de 1880. Nesse período, a atuação do Poder Judiciário no controle de constitucionalidade das normas "limitava-se a um exame formal baseado na repartição de competências estabelecida pelo federalismo canadense ou na compatibilidade de atos do governo central e provinciais com a legislação imperial" (PINTO, 2013, p. 119).

Contudo, a Carta de 1982 inaugurou um novo modelo constitucional no Canadá, e estabeleceu expressamente a possibilidade do Poder Judiciário invalidar atos do Poder Legislativo que fossem contrários aos direitos e garantias nela dispostos (PINTO, 2013; BARBOSA, 2002).

O Controle de Constitucionalidade no Canadá é difuso e, consequentemente, pode ser realizado por qualquer instância do Poder Judiciário, desde a primeira até a Suprema Corte. Contudo, o Governo também pode apresentar à Corte de Apelação ou a Suprema Corte o pedido de revisão de uma norma através do Renvoi, que é um mecanismo que lembra as Ações do Controle Concentrado adotadas no Brasil e que também exigem legitimados específicos para sua propositura (BARBOSA, 2002).

Embora tenha sido firmado um modelo dialógico de jurisdição constitucional, no qual os Poderes Judiciário e Legislativo exercem a função interpretativa das normas, a fim de garantir a proteção dos direitos humanos, tem-se nessa espécie a presença de um fraco mecanismo de controle de constitucionalidade por parte do Poder Judiciário, em que há a competência deste para conhecer e declarar a inconstitucionalidade de atos e normas, mas nem sempre the é dado primazia de opinião sobre os demais Poderes (especialmente o Legislativo) (PINTO, 2013).

O Constitucionalismo da Commonwealth, como também pode ser chamado o modelo adotado no Canadá, leva em consideração os documentos formais de garantia dos direitos fundamentais e a supremacia parlamentar, sendo a sua principal característica a participação contida dos juízes, quando estes atuam na proteção dos 
direitos fundamentais (PINTO, 2013).

Barbosa (2002, p. 141) afirma que esse comportamento contido do Judiciário se dá em razão de que, em tese, as leis editadas pelo Parlamento representam a vontade popular. Nesse sentido afirma Barbosa,

[...] dizer da inconstitucionalidade de uma lei, votada pelo Parlamento, é dizer da vontade inconstitucional do povo. E quem afirma tal coisa são justamente membros de um poder de estado que não estão submetidos ao crivo do voto popular, e que, portanto, teriam em relação aos parlamentares eleitos, um déficit de legitimidade.

Dessa forma, no exercício de suas funções, os juízes tendem atuar sem ofender a supremacia que é reconhecida ao Legislador eleito democraticamente pela população. Por isso, constantemente, os Tribunais reafirmam que o seu papel constitucional não permite com que se pronuncie sobre a sabedoria ou conveniência das leis, isso porque, a sua atuação se restringe, tão somente, a confirmar a constitucionalidade das normas e dos seus efeitos (BARBOSA, 2002).

A atuação contida dos juízes e Tribunais também está relacionada ao disposto no artigo 33 da Carta de 1982, que ficou conhecida como "cláusula não obstante" e que permite ao Legislador, Federal ou Provincial, aplicar lei que contrarie alguns direitos dispostos na Constituição. Isso significa dizer que os governos podem declarar que uma lei ou ato deverão continuar em vigor não obstante o Poder Judiciário tenha declarado sua inconstitucionalidade (YARHI, 2018).

Relembrando-se acerca do Brasil e do quanto o Constituinte foi desconfiado do legislador ao disciplinar muitos direitos como constitucionais, no Canadá também ocorreu essa mesma situação, porém relacionada aos governos provinciais, que estavam preocupados com o fato da Carta de 1982 conceder aos Juízes e Tribunais poderes para interpretá-la e restringir o direito destes governos de editar leis conforme a necessidade local (YARHI, 2018).

A aprovação da Carta, em 1982, apenas ocorreu porque foi incluída referida cláusula resguardando ao Parlamento ou qualquer legislatura provincial a isentar leis de certas seções da Carta no que diz respeito aos direitos fundamentais, de igualdade e legais, por um período de 5 (cinco) anos, passível de renovação caso o entendimento do legislativo permaneça o mesmo (YARHI, 2018). Ao tratar acerca da criação da referida cláusula, Russel (1995, p. 138) ${ }^{1}$ afirma que:

A cláusula não obstante foi inserida na Carta por insistência de políticos, principalmente os provinciais, que queriam um controle democrático e responsável da revisão judicial. Para aqueles que consideram fundamentais, os direitos constitucionais estão sendo levados a sério apenas quando o judiciário pode defendê-los contra as decisões majoritárias dos ramos

\footnotetext{
${ }^{1}$ The legislative override was insert in the Charter at the insistence of politicians, mainly provincial premiers, who wanted an accountable, democratic check on judicial review. To those who believe fundamental, constitutional rights are being taken seriously only when the judiciary can uphold them against the majoritarian decisions of the political branches, the legislative override contradicts the very purpose of the Charter [...]. In practice, the legislative override is hardly ever used.
} 
políticos, a substituição legislativa contradiz o próprio objetivo da Carta [...]. Na prática, a substituição legislativa quase nunca é usada.

Porém, não se verifica que houve pouco uso dessa cláusula desde 1982, pois - Partido Quebecois a invocou para cada fragmento de Lei aprovado na Assembleia de Quebec. Além disso, em 1988, foi invocada para aprovação do Projeto de Lei 178 da Província de Quebec e, em 1986, evocada pelo Primeiro Ministro de Saskatchewan, a fim de suspender greves de trabalhadores locais. Ao longo dos anos, mais de 15 vezes a cláusula foi evocada (YARHI, 2018).

Somada a essa questão, cita-se também o disposto no artigo $1^{\circ}$ da Carta, que afirma não serem absolutos os direitos e liberdades fundamentais, sendo permissivo ao Poder Legislativo, sobretudo os provinciais, editar normas conflitantes com os valores presentes na Carta, mediante a restrição de direitos. Com isso, na tentativa de tornar a Carta mais aceitável pelos órgãos legislativos (federal e provinciais), foi dada certa flexibilidade na aprovação de políticas que potencialmente pudessem entrar em conflito com os direitos nela estabelecidos (PINTO, 2013).

Os artigos $1^{\circ}$ e 33 da Carta canadense de 1982, em certa medida, condicionam a atuação do Poder Judiciário a uma postura contida na resolução das demandas que Ihe são levadas. Contudo, conforme será apresentado, a Suprema Corte do Canadá, enquanto órgão de cúpula do Judiciário, passou por três fases que refletem que o seu comportamento foi ativista, mesmo com a presença desses mecanismos de contenção da sua atuação.

\section{OS FENÔMENOS DO ATIVISMO E DA JUDICIALIZAÇÃO NO CONTEXTO BRASILEIRO E CANADENSE}

Em 1993 o vice-governador do Texas, Bob Bullock, foi à televisão pedir sugestões para lidar com a crise do sistema escolar, que iniciou após uma Emenda Constitucional que determinava a divisão dos fundos de financiamento escolar no Estado. O problema na educação que o Estado do Texas enfrentava foi solucionado por meio de uma decisão judicial que aplicou o entendimento da Suprema Corte do Texas: entendendo que o sistema de educação pública estava em conflito com a 
própria Constituição Estadual e modificando a abordagem da educação no Estado (TATE; VALLINDER, 1995).

O caso apresentado é exemplo do que se passou a vivenciar cada vez mais na interação entre os Poderes do Estado. Na década de 90 do século XX, tem-se um significativo aumento de pesquisas e estudos acerca da expansão do Poder Judiciário, sconstatando-se que houve um aumento desse fenômeno em todo o mundo e que questões de cunho político se tornaram, paulatinamente, a ser objeto de discussão nas instancias judiciais (TATE; VALLINDER, 1995; BARBOZA; KOZICK; 2012).

Carvalho (2004) afirma que no final do século passado, a maioria dos países ocidentais democráticos confiou a um Tribunal Constitucional o poder de controle dos demais Poderes e de interpretação do Texto Constitucional. Com isso, colocou-se no cenário político os Tribunais Constitucionais, e o resultado desta equação é que essa nova arquitetura institucional permitiu o desenvolvimento de um ambiente político com maior participação do Poder Judiciário nos processos decisórios. Esse resultado proporcionou o surgimento dos fenômenos da judicialização e do ativismo judicial.

Inicialmente, será adotado o conceito de Barroso (2012) de judicialização, para o autor a judicialização é o fenômeno em que questões de grande repercussão política e social são debatidas e decididas por órgãos do Poder Judiciário, e não pelas instâncias políticas decisórias tradicionais: o Poder Legislativo e o Poder Executivo. Ou seja, há uma transferência de poder para os Juízes e Tribunais, havendo uma consequente mudança na linguagem decisória, na argumentação e na forma de participação da sociedade em relação ao Judiciário.

Cabe ressaltar que tal conceito não é pacífico, pois também é possível a judicialização como sendo o ato de elaboração de políticas públicas por Juízes e Tribunais, por meio de suas decisões sobre direitos e "da remarcação judicial das fronteiras entre órgãos do Estado" (HIRSCHL, 2009, p. 140).

Tate e Valinder (1995, p. 28)², em pioneiro trabalho sobre a temática, afirmam que a judicialização pode ser considerada como o processo pelo qual Juízes e

\footnotetext{
21 . The process by which courts and judges come to make or increasingly the making of public policies that had previously been made (or, it is widely believed, ought to be made) by other governmental agencies, especially legislature and executives, and; 2 . The process by which nonjudicial negotiating and decision-making forums come to be dominated by quasi-judicial (legalistic) rules and procedures (versão original em ingles).
} 
Tribunais dominam, ou tendem a dominar, a produção de políticas públicas que eram previamente promovidas por outras instâncias governamentais e o processo pelo qual negociações não judiciais tendem a ser controlados por regras e procedimentos quase jurídicos.

Regra geral, a compreensão acerca da judicialização gira em torno da transferência de competências dos Poderes Legislativo e Executivo ao Poder Judiciário, quando este conhece demandas cujo conteúdo está carregado de assuntos políticos que poderiam ser objeto de matéria parlamentar e cujo fundamento decisório está previsto na própria Constituição, que condiciona a este Poder a função de garantir a promoção dos direitos e de protegê-los quando ameaçados (BARROSO, 2012; BARBOZA; KOZICK; 2012; TATE; VALLINDER, 1995).

Hirschl (2009, p. 141) afirma que o fenômeno da judicialização pode se apresentar de diversas formas, não apenas por meio do modelo tradicional das decisões judiciais sobre questões políticas. Para o autor, as perspectivas ou categorias da judicialização são três, que levam em consideração também a:

[...] disseminação de discursos, jargões, regras e procedimentos jurídicos na esfera política e nos fóruns e processos de elaboração de políticas públicas; a judicialização da elaboração de políticas públicas pelas formas "comuns" de controle judicial de constitucionalidade de leis e atos da administração pública; e a judicialização da "política pura" - a transferência, para os tribunais, de assuntos cuja natureza e significado são claramente políticos, incluindo importantes debates sobre a legitimidade de regimes e identidades coletivas que definem (e muitas vezes dividem) comunidades inteiras.

Igualmente, Viaro (2017, p. 234) afirma que a judicialização se trata de um fenômeno complexo que, para além do elemento jurídico, também envolve elementos políticos, institucionais, sociais, econômicos e culturais, "interagindo em diferentes níveis e de variadas maneiras em cada cenário, estabelecendo tendências de ampliação de normatização, expansão do espectro de questões passíveis de deliberação pelos juízes e tribunais e de adoção de métodos jurídicos e judiciais" em espaços não judiciais.

O conceito de judicialização, portanto, pode ser visto a partir da perspectiva dada pela ótica político-institucional, com foco no Estado e nos processos de relação entre os Poderes, comumente intitulada de "judicialização da política", bem como pelo prisma sociocultural, cujo foco é a própria sociedade e os processos de modificação das relações entre seus agentes (VIARO, 2017).

Por se tratarem de perspectivas complementares, é difícil dissociar o aumento da inferência do Poder Judiciário nas questões que tradicionalmente são políticas do próprio aumento da atuação do Poder Judiciário nas questões sociais, tendo em vista 
que um depende do outro e ambos da existência de problemas políticos e sociais que podem se tornar jurídicos.

Em apertada síntese, o conceito de judicialização dado por Viaro (2017, p. 236-237) expressa o que já foi levantado por autores tradicionais como Barroso (2012), Tate e Vallinder (1995) e Hirschl (2009). Dessa forma, o autor afirma que:

[...] a expressão "judicialização da política", em acepção ampla, refere-se ao fenômeno da expansão do poder judicial no âmbito das relações políticas, caracterizado pelo adensamento da regulação jurídica na esfera estatal; o que permite maior interferência do Poder Judiciário na deliberação de questões do âmbito político, ou seja, que até então eram consideradas exclusiva ou precipuamente de alçada dos legisladores e gestores, e a incorporação de argumentos e critérios jurídicos, métodos e procedimentos judiciais, organização e estrutura judiciários fora do âmbito judicial, no próprio âmbito político. Do mesmo modo, em acepção ampla, a expressão "judicialização das relações sociais" refere-se ao fenômeno da expansão do poder judicial no âmbito das relações socioeconômicas, caracterizado pelo aumento geral de regulação e pela incorporação dos métodos e estruturas tipicamente associadas ao Poder Judiciário no seio da vida privada e das organizações particulares, bem como pelo incremento da interferência ou da efetiva transferência, para o Poder Judiciário, de deliberações de questões particulares, como o aumento da demanda por serviços judiciários.

Feitas as considerações acerca da judicialização, passa-se ao estudo do ativismo judicial. Para tanto, será adotado o conceito de Barroso (2012), que o compreende como modo mais específico e mais proativo de atuação do Poder Judiciário quando da interpretação do Texto Constitucional. Nesse sentido, tem-se uma expansão de sentido e alcance em face ao que originariamente está previsto pela norma, sendo esse fenômeno fruto de um período de retratação e de que crise de legitimidade democrática por parte do Poder Legislativo e da classe política como um todo.

As origens do ativismo judicial remontam ao final do século XIX, quando na literatura inglesa uma decisão judicial que possuía natureza inovadora ao ponto de apresentar alguma afronta ao Parlamento era intitulada de legislação judicial (STRAPAZZON; GOLDSCHMIDT, 2013). Contudo, foi apenas em 1947 que o termo ativismo judicial foi utilizado pelo historiador, biógrafo e analista americano Arthur Meier Schelesinger Jr., quando escreveu o artigo “The Supreme Court: 1947” para a revista Fortune. Inicialmente o termo representava uma expressão análoga ao conceito sociológico de ativismo aplicado na atuação dos Juízes da Suprema Corte dos EUA. Dessa forma, o que o autor buscava apresentar enquanto conceito de ativismo como era o comportamento dos membros da Corte face à decisão de 
questões políticas, se eram ativistas judiciais ou autocontidos (STRAPAZZON; GOLDSCHMIDT, 2013).

Ramos e Oliveira Júnior (2016) afirmam que Scheleisinger Jr. promoveu um grande acerto para a construção do termo ativismo relacionando-o com a atuação da Corte Americana, bem como abriram as portas para que tanto os defensores quanto os críticos ao fenômeno pudessem utilizá-lo sem estabelecer com rigor uma conceituação ao termo.

O conceito de ativismo, assim como o de judicialização flutua bastante e é demarcado como positivo e negativo a depender de quem esteja discorrendo acerca dele. Contudo, Barroso (2012, p. 25) apresenta um conceito do que seria o ativismo judicial e, para tanto, este será adotado como modelo para expor referido fenômeno. Assim, o ativismo judicial:

[...] é uma atitude, a escolha de um modo específico e proativo de interpretar a Constituição, expandindo o seu sentido e alcance. Normalmente ele se instala em situações de retração do Poder Legislativo, de um certo descolamento entre a classe política e a sociedade civil, impedindo que as demandas sociais sejam atendidas de maneira efetiva. A ideia de ativismo judicial está associada a uma participação mais ampla e intensa do Judiciário na concretização dos valores e fins constitucionais, com maior interferência no espaço de atuação dos outros dois Poderes.

Dessa forma, Barroso (2012) afirma que o ativismo judicial manifestar-se-ia, então, por meio de diferentes situações: a) aplicação da Constituição de maneira direta a hipóteses não expressamente previstas e sem haver qualquer manifestação por parte do Legislativo; b) controle da constitucionalidade de leis e atos normativos com base em critérios mais flexíveis, que a clara e direta violação ao texto da Constituição da República brasileira de 1988; c) imposição de decisões, condutas ou de abstenções aos órgãos do Estado, sobretudo em questões de políticas públicas.

Para Baum (1987), que entende o ativismo sob uma perspectiva mais neutra e ampla do Poder Judiciário, o ato de declaração de inconstitucionalidade de leis, assim como 0 ato de interpretação da norma sem que, necessariamente, haja o reconhecimento de inconstitucionalidade do dispositivo são condutas ativistas. Nesse sentido, o autor verifica que o ativismo reside na possibilidade do Poder Judiciário tomar atitudes que conflitem com decisões políticas dos Poderes Legislativo e Executivo e com atos de interpretação das normas sem a declaração de sua 
inconstitucionalidade.

Para Dworkin (2011), o ativismo se trata de uma conduta que ignora o Texto Constitucional, na medida em que o juiz põe em xeque todos os seus princípios, sua história, as decisões da Corte Judicial etc., para aplicar o seu próprio entendimento e seu ponto de vista sobre o que a justiça determina que seja realizado. Embora seja reconhecidamente como defensor do judicial review, o autor caminha em um sentido de atuação dos juízes pautado na norma, no texto da lei e na Constituição.

Em sentido oposto, caracterizando o ativismo judicial negativamente, Ramos (2010, p. 129) assevera que se trata de uma desnaturação da função típica do Poder Judiciário em detrimento dos outros Poderes e corrobora afirmando que por:

[...] ativismo judicial deve-se entender o exercício da função jurisdicional para
além dos limites impostos pelo próprio ordenamento que incumbe,
institucionalmente, ao Poder Judiciário fazer atuar, resolvendo litígios de
feições subjetivas (conflitos de interesse) e controvérsias jurídicas de
natureza objetiva (conflitos normativos). Há, como visto, uma sinalização
claramente negativa no tocante à práticas ativistas, por importarem na
desnaturação da atividade típica do Poder Judiciário, em detrimento dos
demais Poderes.

Observa-se que diversos autores possuem acertados conceitos e posições acerca do ativismo judicial, porém chama-se atenção ao que Barroso (2012) afirma acerca dos limites existentes entre a judicialização e o ativismo judicial. O autor afirma que a judicialização se trata de uma circunstancia que decorre em razão do modelo constitucional adotado que disciplina ao Poder Judiciário a consecução dos princípios constitucionais e a garantia dos direitos fundamentais previstos na Carta Constitucional, e que, consequentemente, ao realizar, poderá ingressar em assuntos políticos que possam em algum momento levar a um remodelamento das fronteiras entre os Poderes do Estado. Por outro lado, quando conceitua que o ativismo se trata de uma escolha dos Juízes de atuar de modo específico e proativo, confirma que a escolha em assim agir vai de encontro à moldura de repartição dos poderes e competências pensada por Montesquieu (BARROSO, 2012) e adotada em diversos países, como o Brasil e Canadá. 


\subsection{ANÁLISE COMPARATIVA A PARTIR DAS EXPERIÊNCIAS DO STF E DA SUPREMA CORTE CANADENSE EM FACE DA JUDICIALIZAÇÃO E DO ATIVISMO JUDICIAL}

Ao se realizar um estudo comparado entre os Judiciários do Brasil e do Canadá, verifica-se que em ambas as Cortes, STF brasileiro e Suprema Corte do Canadá, houve uma expansão dos seus papéis, de modo que passaram a tratar de questões de cunho político, moral, religioso, sexual entre outros, que, em tese, deveriam ser discutidas pelos Poderes Executivo e Legislativo no Brasil e pelo Parlamento e pelo Primeiro Ministro e Rainha Elizabeth II no Canadá (BARBOZA; KOZICK, 2012).

No Canadá, em razão da Carta 1982, verifica-se que a Suprema Corte assumiu um interesse especial em questões constitucionais e mitigou desde a sua primeira decisão a ideia do formalismo interpretativo inglês, do passivismo judicial e da ideia de supremacia parlamentar, apresar do disposto nos artigos $1^{\circ}$ e $33 \mathrm{da}$ referida Carta (CAMPOS, 2014).

Desde a edição da Carta de 1982, se observa que a Suprema Corte do Canadá passou por três momentos distintos cujos reflexos podem ser vistos diretamente nas decisões jurisprudenciais por ela emitidas. O primeiro momento, que representa os primeiros anos de vigência da Carta. O segundo, que representa o caso R. v. Oakes, de 1986. O terceiro que aponta as decisões mais recentes da Corte (PINTO, 2013).

Nos primeiros anos de atuação da Corte sob a Carta de 1982, constatou-se uma abrangente proteção dos direitos, a negação da interpretação restrita dos direitos fundamentais e a afirmação explícita de que compete a Suprema Corte realizar a guarda da Carta Constitucional. Embora houvesse receio de que a Corte tivesse um comportamento refreado na proteção aos direitos, esse temor não se confirmou (CAMPOS, 2014).

Em razão de a Carta dispor que o Judiciário deve promover a máxima eficácia dos direitos fundamentais e buscar o propósito de cada direito que nela há disposto, a Corte passou a adotar uma postura proativa e ativista, se comparada com os anos anteriores, cuja atuação era mais contida e restrita. 
Durante esse período, a Corte afirmou que os direitos previstos na Carta deveriam ser interpretados de forma "generosa" (generous interpretation) e "finalística" (purposive interpretation). Isso implica dizer que, a partir dessas formas de interpretação os direitos garantidos na Carta não seriam mitigados face aos poderes federais e provinciais e que os propósitos e finalidades de cada direito deveriam ser buscados e, consequentemente, afastadas as atividades que não promovessem os direitos dispostos na Carta (PINTO, 2013).

Por exemplo, em 1984 a Corte do Canadá decidiu o caso AG. Quebec v. Quebec Association of Protestant School Boards, no qual a se discutia a constitucionalidade de uma lei da referida província que buscava restringir o acesso de crianças às escolas públicas anglófonas. De pronto foi declarada a inconstitucionalidade desta lei em razão de haver violação do artigo 23 da Carta, que assegura educação pública em inglês ou francês aos filhos de cidadãos cuja língua principal é aquela minoritária no local (PINTO, 2013).

A partir do julgado, percebe-se que a Corte apresentava um comportamento atuante na proteção dos direitos dispostos na Carta e colocados em xeque por leis a atos normativos editados pelo Poder Legislativo em nível provincial e federal também. Contudo, Pinto (2013, p. 130) afirma que a Corte, mesmo possuindo uma postura ativista, "evitou enfrentar a análise da razoabilidade das medidas legislativas questionadas", e consequentemente, iniciou nesse momento o segundo período de formulação de suas decisões, que passaram a reconhecer a restrição de direitos previstos na Carta face às medidas legislativas nela questionadas.

Neste segundo momento, a Corte observou que teria de enfrentar questões de políticas governamentais que iam de encontro com os direitos assegurados na Carta de 1982. Para tanto, por meio da aplicação do princípio da proporcionalidade, passou a avaliar se referidos direitos poderiam ser objeto de restrição em razão de objetivos gerais ou coletivos que apresentavam maior importância. Em decisão do caso $R v$. Oakes, ocorrido em 1986, a Corte estabeleceu os parâmetros no qual o legislador deve observar para restringir, razoavelmente, direitos e liberdade.

Campos (2014, p. 81) menciona que 4 (quatro) foram as balizas dadas pela Suprema Corte no referido caso e que o resultado deu origem ao teste da proporcionalidade das leis, em que, objetivando a lei perseguir a finalidade para qual 
foi criada sem que restrinja direitos de maneira desproporcional, ela será considerada constitucional, desde que observe o seguinte:

[...] (1) a lei restritiva deve perseguir um objetivo importante; (2) a restrição deve ser racionalmente conectada com esse objetivo; (3) a lei deve restringir o direito não mais que o necessário para alcançar o objetivo; (4) a restrição não deve ter um efeito desproporcionalmente severo para seus destinatários.

Por fim, o terceiro momento da Corte é tido como moderado, no qual o comportamento dos juízes se aproxima muito mais da autocontenção que do ativismo judicial. Isso porque, após a decisão dada pela Corte no caso Oakes, se deixou uma margem muito pequena para a edição de normas pelo Parlamento e, consequentemente, ampliada a liberdade dos juízes para decidir acerca de questões que, em regra, são afetas ao poder público (PINTO, 2013).

Com efeito, em pese a doutrina apresentar a atuação da Suprema Corte canadense nesses três momentos considerando sua atuação ora como ativista e ora como refreada, verificam-se alguns casos polêmicos decididos, nas últimas duas décadas do século XX e início do século XXI, em que a Corte assume uma postura ativista e proativa, não perfazendo em sua inteireza o engessamento dado por essa interpretação. Dessa forma, não necessariamente a Corte sempre assumiu um papel retraído ou ativista, para tanto, apresenta-se alguns casos em que a Corte canadense atuou ativamente:

a) Caso $R$ v. Morgentaler (1988): a Suprema Corte considerou inconstitucional a provisão de aborto no Código Penal, pois violava o direito da mulher, conforme disposto na Seção 7 da Carta de 1982. Embora a Corte tenha afirmado que o aborto não havia sido reconhecido como direito constitucional, no Canadá, não há criminalização do aborto, pois até o momento nenhuma lei foi aprovada pelo Parlamento a fim de delimitar tal direito;

b) Caso Vriend v. Alberta (1998): a Suprema Corte decidiu que omissão legislativa pode se tratar de violação da Carta de 1982 e que poderá haver intervenção judicial para conceder direito ou liberdade não prevista na Carta. A decisão da Corte se fundamentou na história de um professor da província de Alberta que foi demitido do seu emprego em razão de sua orientação sexual. Ao tentar realizar boletim de ocorrência na em razão do fato, não conseguiu, pois a Lei de Proteção de Direitos Individuais de Alberta não regulamentava o crime de discriminação por orientação sexual.

c) Caso $M v . H$ (1999): a Corte canadense entendeu que casais homoafetivos devem receber o mesmo tratamento que os casais heterossexuais e determinou, 
então, que todas as províncias editassem suas normas a fim de abranger também a população homoafetiva como portadores de direitos equivalente aos casados legalmente e igualdade de tratamento nos processos de separação. A decisão repercutiu na forma como a Carta e a Lei de Direito da Família das províncias são interpretadas.

d) Caso Chaoully v Quebec (2005): a Corte decidiu que pacientes que esperam por longo tempo para atendimento hospitalar estão sendo violados em seus direitos à vida e à segurança. A decisão foi fundamentada após o médico Jacques Chaoulli ser impedido de fornecer consultas domiciliares utilizando seguro de saúde privado de seus pacientes, pois a cobrança de seguro de saúde na província de Quebec é ilegal, tendo em vista que o governo local oferece saúde gratuita aos seus cidadãos. A decisão é aplicável apenas à província de Quebec e os reflexos da decisão levantaram a fragilidade do sistema de saúde do Canadá e levou outras províncias a reverem seus sistemas.

Os precedentes apresentados demonstram que a Suprema Corte do Canadá possui uma atuação bem ativista e que julga casos de cunho político cujos reflexos são vistos em toda a extensão do país, desde a forma como a Carta de 1982 pode ser interpretada pelo Poder Legislativo na formulação de leis até mesmo no sistema de saúde de suas províncias.

Acerca da atuação do STF no Brasil, tem-se uma Corte cuja finalidade precípua dada pela Constituição da República de 1988 é a guarda da Constituição, que, por meio de suas decisões, promoverá equilíbrio entre as Instituições do Sistema de Justiça, na medida em que exerce com afinco a suas funções e também a segurança jurídica necessária a manutenção da ordem. Contudo, verifica-se que a atuação do referido órgão em por objeto compensar a inércia do Poder Legislativo e do Executivo na consecução de suas funções (RAMOS, 2016). As decisões decorrentes do STF representam o que se afirmou:

a) ADPF no 54 (2012): foi dado o entendimento pelo STF de que a interrupção terapêutica da gestação de feto anencéfalo é conduta que não se encaixa nos artigos 124, 126 e 128, incisos I e II do Código Penal brasileiro. Na medida em que o Tribunal concedeu a possibilidade de realizar aborto de bebês anencéfalos, em certa medida ampliou as hipóteses legais em que referido procedimento poderia ser realizado sem que seja considerado crime.

b) ADI 3.510 (2008): o STF decidiu que realizar pesquisas com célulastronco embrionárias não violam o direito á vida e a dignidade da pessoa humana. Nesse sentido, foi firmada decisão declarando a constitucionalidade do artigo $5^{\circ}$ da Lei de Biossegurança;

c) ADO 26 (2019) e MI 4733 (2019): respectivamente, o STF decidiu que 
os crimes cometidos contra pessoas homossexuais em razão de sua conduta sexual sejam tidas como condutas homofóbicas e transfóbicas, bem como reconheceu que condutas homofóbicas e transfóbicas enquadram-se na tipificação do crime de racismo.

Comparando a atuação da Corte canadense com a do STF no Brasil, é possível verificar que são dois Tribunais cuja atuação está vinculada diretamente com o fatores que Tate e Vallinder (1995) apontam como propulsores da expansão judicial no mundo, quais sejam: a democracia, a separação dos poderes, a politica de direitos, a presença de grupos de interesse nas Cortes Supremas, a presença de grupos de oposição nas Cortes Supremas, instituições majoritárias ineficazes, as percepções das instituições formuladoras de políticas públicas e a delegação (deliberada) das instituições majoritárias.

O que se observa nesses países é que suas Cortes estão evocando para si competências dos Poderes Legislativo e Executivo que, claramente, não há como serem concretizados sem que haja a quebra do princípio da Separação dos Poderes e o reforço da falta de confiança popular nas instituições do Sistema de Justiça do Brasil e do Canadá, na medida em que o Poder Judiciário não está recoberto pela escolha popular e, consequentemente, não é entendido como legitimado a atuar em nome de todos no cenário político.

\section{CONCLUSÃO}

A guisa de conclusão Ramos, Mattos e Cruz destacaram que nos dois últimos dois séculos houve diversos deslocamentos das práticas jurídicas que determinam a expansão do "saber/poder jurídico" para outras esferas da vida, ampliando seus modos de intervenção. Para os autores, tal pressuposto indica claramente uma indissociabilidade, entre as práticas judiciárias e a constituição do homem moderno, pelas ações de modificação e de produção dos modos de vida.

Nesse diapasão, o protagonismo do Poder Judiciário no mundo representou o auge de um processo de fragilização das instituições majoritárias, da busca pela concretização de direitos fundamentais cada vez mais amplos, imprevisíveis e visibilizados, mas, fundamentalmente, em virtude do fortalecimento do movimento que tornou o Poder Judiciário a instituição mediadora do viver. 
No caso do Brasil e de seu Poder Judiciário, observou-se uma estruturação e atribuição de competências que favoreceram o aumento da importância e do papel dos juízes e Tribunais após a promulgação da Constituição da República de 1988, uma vez que a constitucionalização de diversos direitos fundamentais e o aumento da consciência da população acerca de tais direitos levaram a um considerável crescimento no número de demandas judicializadas para a sua obtenção.

No caso específico do STF brasileiro, essa instituição apresenta-se como o órgão de cúpula e, portanto, como um dos principais responsáveis por esse novo perfil proativo e pelo protagonismo em pautas de caráter político assumidos pelo Judiciário brasileiro. Seu poder e influência despontaram ainda mais após a promulgação da Emenda Constitucional n. 45 do ano de 2004, em razão da criação de institutos como os enunciados de Súmula Vinculante e a Repercussão Geral em sede de Recurso Extraordinário.

Com relação ao Poder Judiciário canadense, observou-se que, por vínculo com a Inglaterra, adotava-se o princípio da Soberania do Parlamento até o momento em que o Canadá passou a gozar de autonomia política. A partir de então, sobretudo após a Carta de 1982, adotou-se um modelo de constitucionalismo em que o próprio Legislador tornou-se limitado aos preceitos constitucionais, podendo o Judiciário declarar a invalidade de leis e atos normativos que com eles fossem incompatíveis.

No caso da Suprema Corte do Canadá, percebe-se que a instituição assumiu um protagonismo justamente a partir da Carta de 1982, não se limitando a uma mera análise de compatibilidade formal das leis em relação à Constituição, mas também expandindo o caráter de suas decisões e passando a debater e a decidir assuntos tradicionalmente de responsabilidade do Parlamento.

Com relação aos conceitos de Judicialização e Ativismo Judicial, concluiu-se que ambos derivam do fenômeno da expansão da autoridade do Poder Judiciário observado desde a década de 90 em diversos países. Porém, diferentes autores adotam distintas compreensões acerca de cada um dos dois conceitos.

Compreende-se, nesse sentido, que as questões da judicialização da política e do ativismo judicial repousam onde assuntos de Direito se entrelaçam com outros assuntos que podem ser ou não do Direito, mas perpassam por ele e, muitas vezes, se fundamentam nele. Observa-se, conforme Barroso (2012) que há certa fluidez da 
fronteira entre a política e a justiça no mundo contemporâneo, sendo potencializada essa questão, sobretudo nos países democráticos, onde o Poder Judiciário, no exercício de suas competências precisa tratar de temas afetos não só ao Direito, mas também à política, moral, religião etc.

Por fim, o STF e a Suprema Corte Canadense encontram-se no epicentro da Judicialização e do Ativismo Judicial em seus respectivos países, ditando os rumos dos Judiciários por eles comandados, dando nova conotação aos conceitos tradicionais de controle de constitucionalidade e judicial review e expandindo sua autoridade para temáticas envolvendo questões polêmicas e com forte conteúdo político.

\section{REFERÊNCIAS}

BARBOSA, Claudia Maria. Os novos oráculos da lei: a experiência do modelo misto canadense e a proposta da súmula de efeito vinculante no Brasil. Tese (doutorado) - Direito (Curso de Pós-graduação em Direito da Universidade Federal de Santa Catarina). Universidade Federal de Santa Catarina, 2002.

BARBOZA, Estefânia Maria de Queiroz. KOZICKI, Katya. Judicialização da Política e controle judicial de políticas públicas. Revista de Direito GV, São Paulo, n. 8, jan-jun, 2012, p. 059-086.

BARROSO, Luis Roberto. Judicialização, Ativismo Judicial e Legitimidade Democrática. [Syn]Thesis, Rio de Janeiro, vol.5, no 1, 2012, p.23-32.

BRASIL. Constituição da República Federativa do Brasil. 5 de outubro de 1988.

Disponível em: <https://www.planalto.gov.br/ccivil_03/constituicao/constituicao.htm>.

Acesso em: 17 de novembro de 2019.

BAUM, Lawrence. A Suprema Corte Americana: uma análise da mais notória e respeitada instituição judiciária do mundo contemporâneo. Rio de Janeiro, Forense, 1987.

CAMPOS, Carlos Alexandre de Azevedo. Dimensões do ativismo judicial do Supremo Tribunal Federal. Rio de Janeiro: Forense, 2014.

CANADA, Supreme Court of Canada. Role of the Court. 2017. Disponível em: <https://www.scccsc.ca/court-cour/role-eng.aspx>. Acesso em: 10 de dezembro de 2019.

CARVALHO, Ernani Rodrigues de. Em busca da judicialização da política no Brasil: apontamentos para uma nova abordagem. Rev. Sociol. Polít., Curitiba, 23, p. 115-126, nov., 2004.

DWORKIN, Ronald. O Império do Direito. Trad. Jefferson Luiz Camargo e versão técnica Gildo Sá Leitão Rios. 2ª ed. São Paulo: Martins Fontes, 2011.

FERREIRA FILHO, Manoel Gonçalves. Poder Judiciário na Constituição de 1988: Judicialização da política e politização da justiça. R. Dir. Adm., Rio de Janeiro, n. 198, out./dez., 1994, p.1-17.

GALL, Gerald L. The Canadian Encyclopedia. Judiciary in Canada. 2017. Disponível em: $<$ https://www.thecanadianencyclopedia.ca/en/article/judiciary>. Acesso em: 12 de dezembro de 2019.

HIRSCHL, Ran. O novo constitucionalismo e a judicialização da política pura no mundo. Revista de 
Direito Administrativo, Rio de Janeiro, v. 251, p. 139-178, mai. 2009.

MATTOS, Delmo; RAMOS, Edith; CRUZ, Saile Azevedo da. A judicialização da saúde e a gestão biopolítica da vida: O Poder Judiciário e as estratégias de controle do sistema de saúde. Rev. Direito Práx., Rio de Janeiro, v. 10, n. 3, p. 1745-1768, Sept. 2019. Available from <http://www.scielo.br/scielo.php?script=sci_arttext\&pid=S217989662019000301745\&lng=en\&nrm=iso>. access on 18 Dec. 2019. Epub Sep 16, 2019. http://dx.doi.org/10.1590/2179-8966/2018/33610.

PINTO, José Guilherme Berman Correa. Direito Constitucional Comparado e Controle Fraco de Constitucionalidade. Tese (Doutorado em Direito) - Departamento de Direito, Pontifícia Universidade Católica do Rio de Janeiro. Rio de Janeiro, 2013.

RAMOS, Elival da Silva. Ativismo judicial: parâmetros dogmáticos. São Paulo: Saraiva, 2010.

RAMOS, Paulo Roberto Barbosa Ramos. OLIVEIRA JÚNIOR, Jorge Ferraz de. Características do Ativismo Judicial nos Estados Unidos e no Brasil. In: Org. RAMOS, Paulo Roberto Barbosa. Direito Constitucional Americano. São Luís: EDUFMA, 2016.

RODRIGUES, Amanda Carolina Buttendorff; BARBOSA, Claudia Maria. Cortes Constitucionais - um estudo comparado. In: CONPEDI. (Org.) ACESSO À JUSTIÇA, 1ed. CONPEDI, 2012, v.1, p. 512-540.

RUSSEL, Peter H. Canadian Constraints on Judicialization from Without In: TATE, C. N.; VALLINDER, T. (Eds.). The Global Expansion of Judicial Power. New York/ London: New York University Press, 1995.

SADEK, Maria Tereza Aina. Poder Judiciário: perspectivas de reforma. Opinião Pública, Campinas, vol. X, n. 1, maio, 2004, p. 01-62.

SILVA, José Afonso da. Curso de Direito Constitucional Positivo. São Paulo: Malheiros, 2016. STRAPAZZON, Carlos Luiz. GOLDSCHMIDT, Rodrigo. Teoria constitucional e ativismo político: problemas de teoria e de prática com direitos fundamentais sociais. Revista Facultad de Derecho y Ciencias Políticas, 2013, vol. 43, n. 119, p. 567-624.

TATE, Chester Neal; VALLINDER, Torbjörn. The global expansion of judicial power: the judicialization of politics. In: TATE, C. N.; VALLINDER, T. (Eds.). The Global Expansion of Judicial Power. New York/ London: New York University Press, 1995.

VERISSIMO, Marcos Paulo. A Constituição de 1988, vinte anos depois: Suprema Corte e Ativismo Judicial "à brasileira". Revista Direito GV. São Paulo, jul. - dez. 2008, p. 407-440.

VIARO, Felipe Albertini Nani. Judicialização, ativismo e interpretação constitucional. Interpretação constitucional no Brasil. São Paulo: Escola Paulista da Magistratura, p. 231-253, 2017.

VIEIRA, Oscar Vilhena. Supremocracia. Rev. direito GV, Dez. 2008, v. 4, n. 2, p.441-463.

YARHI, Eli. The Canadian Encyclopedia. Notwithstanding Clause. 2018. Disponível em: <https://www.thecanadianencyclopedia.ca/en/article/notwithstanding-clause>. Acesso em: 12 de dezembro de 2019. 